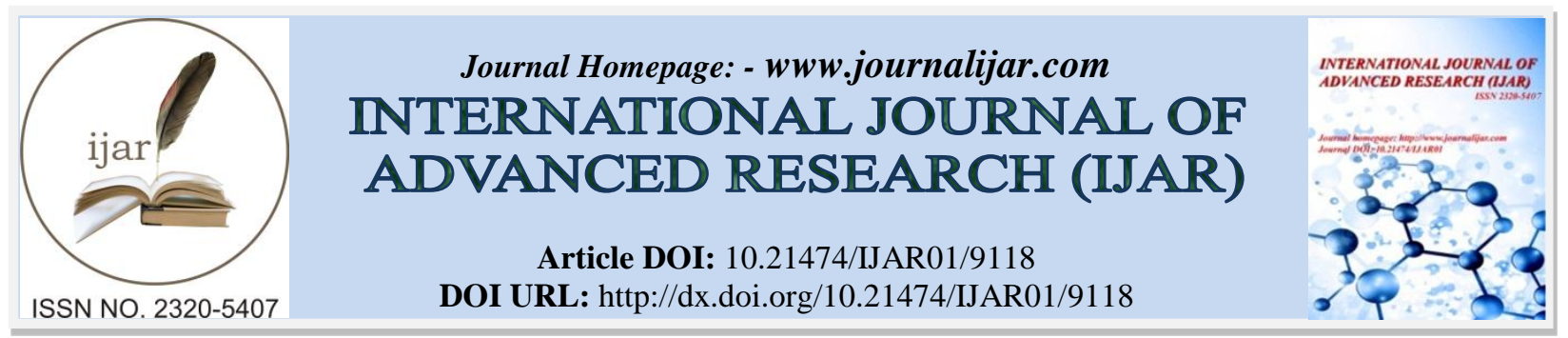

RESEARCH ARTICLE

\title{
INVESTIGATING THE EFFECT OF NMP/PHENOL SOLVENT BLEND ON LUBRICATING OIL PROPERTIES WITHOUT/WITH USING SURFACTANT.
}

Rehab M. El-Maghraby.

Faculty of petroleum and mining engineering, Suez University, Suez, Egypt.

\section{Manuscript Info}

\section{Manuscript History}

Received: 22 March 2019

Final Accepted: 24 April 2019

Published: May 2019

Key words:-

Lubricating Oil, Solvent Extraction, Phenol, NMP, Surfactant, Viscosity Index.

\begin{abstract}
In this study, solvent extraction of lubricating oil to improve its viscosity index is investigated. A blend of phenol/NMP co-solvent was tested at different feed to solvent ratio 1:1, 1:1.5 and 1:2. Different percent of phenol $(25 \%, 50 \%$ and $75 \%)$ in the co-solvent were studied. The conradson carbon residue, refractive index, viscosity at $40{ }^{\circ} \mathrm{C}$ and $100{ }^{\circ} \mathrm{C}$, viscosity index and \%yield of raffinate were measured. It was found that at constant extraction temperature of $65{ }^{\circ} \mathrm{C}$ and at constant mixing time of 15 minutes, best solvent blend was $25 \%$ phenol- $75 \%$ NMP.

Moreover, the effect of extraction temperature on the quality of raffinate was investigated using 25\% phenol-75\% NMP solvent blend and feed to solvent ratio of $1: 2$. Extraction temperatures up to $112{ }^{\circ} \mathrm{C}$ were tested. An optimum temperature of $103{ }^{\circ} \mathrm{C}$ was reached after which a deterioration in the quality of the raffinate is observed. Using surfactant as an additive in small quantities $(0.01,0.02,0.05$ and 0.1 wt.\%) in the presence of $25 \%$ phenol-75\%NMP as a solvent was studied. Temperature was held constant at $103{ }^{\circ} \mathrm{C}$ and feed to solvent ratio of 1:2 was used. An improvement in the properties of the raffinate was observed
\end{abstract}

Copy Right, IJAR, 2019,. All rights reserved.

\section{Introduction:-}

The market size for lubricating oil in continuously expanding, in 2018 it reached 128.51 billion US Dollars [1]. Increasing demand on lubricating oil has reached 36.1 million metric tons in 2017 [2]. This increase in demand has driven more expansion in production and new technology adaptation to meet such demand while maintaining economic value. Lubricating oil is hydrocarbon-based oil consisting of paraffins, iso-parrafins, naphthenes and aromatics. Naphthenic based oil has low viscosity index and pour point while paraffinic based oil has high viscosity index and high pour point. After fractional distillation of crude oil, the resulting long residue is sent to vacuum distillation, where lubricating oil is separated into four main fractions; spindle distillate (SPD), medium and heavy neutral distillate (MND and HND) and bright stock (BS). The four fractions are different in their boiling temperature range and viscosity.

Following vacuum distillation, the lubricating oil is deasphalted to remove asphaltenes and resins, then solvent extraction is conducted to reduce the viscosity index, reduce the aromatic content and improve lubricating oil quality. Dewaxing of lubricating oil either by using solvent or through catalytic dewaxing is carried to remove the wax content in the lubricating oil. Normal paraffins have high viscosity index, in the same time, their presence in 
lubricating oil increases its pour point, hence, they have to be removed. The final step is to adjust the color and stability of lubricating oil by clay treatment or hydro-finishing [3].

In the late 1920s solvent extraction was introduced as a way to treat lubricating oil. Through this process undesired compounds in the lubricating oil is removed using solvents that have certain characteristics. Nowadays also, solvent extraction of lubricating oil is employed on a wide commercial scale. Tailored solvent that can remove all the undesired product has not been found yet, hence, analysis and studies are conducted to find the most suitable solvent or combination of solvent to reach the required lubricating oil specifications. Major solvent that are currently being used is NMP (N-methyl-2-pyrrolidone), furfural and phenol [3-5].

By using solvent extraction, the viscosity index of the lubricating oil will improve in addition to the oxidation resistance and color. Heavy aromatic compounds have low viscosity index, low lubricating ability and low oxidative and thermal stability. This means that lubricating oil containing high molecular weight aromatic compounds, will has less stable viscosity that will deteriorate with the change in temperature, hence, it will not fulfill its job as a lubricant. By extracting aromatic compounds from lubricating oil, the viscosity index will improve and the overall lubricating oil quality will be enhanced. Other properties will be affected by solvent extraction such as viscosity, refractive index, color and conradson carbon residue.

A good solvent will be highly selective to aromatic compounds and will possess good solvent power. In addition, it will have good stability and be easily recoverable. Different solvents and co-solvents where investigated in the literature. The effect of furfural as a solvent on a mixed base oil was investigated by [6-8]. Different extraction temperature and solvent to feed ratio were studied. An improvement in the oil viscosity index was observed with the increase in extraction temperature and solvent to oil ratio. A viscosity index of 115.6 was reached at $110{ }^{\circ} \mathrm{C}$ extraction temperature and at 4:1 solvent to oil ratio.

In addition, NMP and furfural were studied in [9] as a single solvent to extract the polyaromatics compounds from lubricating oil, up to 4:1 solvent to feed ratio was tested. A 107.82 viscosity index was obtained using NMP at 110 ${ }^{\circ} \mathrm{C}$, while a viscosity index of 101 was reached when using furfural at the same temperature. This confirms the higher selectivity of NMP compared to furfural. In [10] the extraction of aromatic compounds from lubricating oil using co-solvents formamide/furfural and NMP/furfural were investigated. It was found that viscosity index value of 96 and $68.5 \%$ yield was achieved using 1:2 feed to $\mathrm{NMP} /$ furfural co-solvents ratio at $110{ }^{\circ} \mathrm{C}$. While lower viscosity index of 102 and higher yield of $69.23 \%$ were obtained when using 1: 1.5 feed to formamide/furfural co-solvents ratio at extraction temperature of $90{ }^{\circ} \mathrm{C}$.

According to [11-14] using surfactant in the solvent extraction process will increase the mass transfer coefficient while simultaneously decrease the interfacial area. Surfactant as an additive in solvent extraction of lubricating oil was studied in [15]. It was found that the addition of surfactant enhanced the extraction of polyaromatic compounds and increased solvent selectivity [16-17]. Furfural performance was improved by the addition of 0.01 to $0.1 \mathrm{wt} \%$ sodium lauryl ether sulfate (SLES) at optimum extraction temperature of $70{ }^{\circ} \mathrm{C}$ and an increase in the yield was observed [16-17].

It is clear from the literature that NMP is highly selective but in the same time its operating cost is high compared to that of phenol. On the other hand, one of the drawbacks of using phenol as single solvent is its toxicity. Using phenol as co-solvent with NMP will reduce the toxicity of phenol in the solvent mixture, this has not been investigated in the literature before.

In this work a co-solvent containing different ratios of phenol/NMP are tested, in addition the feed to solvent ratio was investigated. The effect of such variation on refractive index, viscosity, viscosity index, conradson carbon and yield were studied. In addition, the optimum blend and the optimum extraction temperature were identified. Moreover, the effect of using surfactant, sodium lauryl sulfate (SLS) as an additive to NMP/Phenol solvent mixture was studied.

\section{Materials and Methodology:-}

\section{Materials:}

Lubricating oil sample of specification listed in Table 1 was used for our study. Egyptian standards for lubricating oil were listed in Table 1, and checked to identify the off specifications lubricating oil properties. NMP of purity of 
99\% (Sigma-Aldrich) and Phenol of 99\% purity (Sigma-Aldrich) were used. The specifications of NMP and Phenol are listed in Table 2. Sodium laureth sulfate (SLS) of purity $99 \%$ was also used.

Table 1: Specifications of untreated lubricating oil sample versus Egyptian lubricating oil standards.

\begin{tabular}{|c|c|c|c|c|}
\hline Specifications & Units & Method & $\begin{array}{c}\text { Egyptian Standard } \\
\text { Limit }\end{array}$ & $\begin{array}{c}\text { Lubricating Oil } \\
\text { Sample }\end{array}$ \\
\hline ASTM Color & & D1500 & 1.5 (Max.) & 3.5 \\
\hline Specific gravity @ 60/60 ${ }^{\circ} \mathrm{C}$ & $\mathrm{g} / \mathrm{cm}^{3}$ & D4052 & - & 0.887 \\
\hline Viscosity @ 100 ${ }^{\circ} \mathrm{C}$ & $\mathrm{cSt}\left(\mathrm{mm}^{2} / \mathrm{s}\right)$ & D 445 & 4 & 5.2 \\
\hline Viscosity@ $90^{\circ} \mathrm{C}$ & & D 445 & 20 & 34.8 \\
\hline Viscosity index & & D 2270 & 95 (Min.) & 67 \\
\hline Boiling Point & ${ }^{\circ} \mathrm{C}$ & - & - & $350-400$ \\
\hline Flash point & ${ }^{\circ} \mathrm{C}$ & D 93 & 149 (Min.) & 155 \\
\hline Pour point & ${ }^{\circ} \mathrm{C}$ & D 97 & -6 (Min.) & -6 \\
\hline Refractive Index @ 20 ${ }^{\circ} \mathrm{C}$ & & D1218 & - & 1.4700 \\
\hline Conradson Carbon & wt.\% & D189 & 0.015 (Max.) & $\mathbf{0 . 0 3 8}$ \\
\hline Ash content & wt.\% & D 482 & 0.01 (Max.) & 0.01 \\
\hline Acidity & $\mathrm{mgKOH} / \mathrm{g}$ & D664 & 0.05 (Max.) & 0.04 \\
\hline Sulfur content & wt.\% & - & 0.068 (Max.) & 0.062 \\
\hline
\end{tabular}

Table 2: Specifications of Phenol and NMP used in our experiments.

\begin{tabular}{|l|c|c|c|}
\hline \multicolumn{1}{|c|}{ Specifications } & Units & Phenol & NMP \\
\hline Purity & $\%$ & 99 & 99 \\
\hline ASTM Color & - & 25 & 40 \\
\hline Specific gravity @ $\mathbf{~ 5 5 ~}^{\mathbf{0}} \mathbf{C}$ & $\mathrm{g} / \mathrm{cm}^{3}$ & 1.08 & 1.027 \\
\hline Viscosity @ 25 ${ }^{\mathbf{C}} \mathbf{c P}$ & 1.58 & 1.65 \\
\hline Saybolt Viscosity @ 140 ${ }^{\mathbf{0}} \mathbf{C}$ & $\mathrm{cPoise}$ & 2.58 & 1.02 \\
\hline Refractive Index @ 20 ${ }^{\mathbf{0}} \mathbf{C}$ & - & 1.5425 & 1.4690 \\
\hline Boiling Point & ${ }^{\circ} \mathrm{C}$ & 182 & 202 \\
\hline Flash Point & ${ }^{\circ} \mathrm{C}$ & 79 & 95 \\
\hline Crystallization point & ${ }^{\circ} \mathrm{C}$ & 40.6 & \\
\hline Freezing point & ${ }^{\circ} \mathrm{C}$ & 40.9 & -25 \\
\hline Water content & $\%$ & 0.1 & 0.04 \\
\hline Critical temperature @ $\mathbf{1 : 1}^{\mathbf{0}} \mathbf{C}$ & & $66.8^{[18]}$ & 232 \\
\hline
\end{tabular}

\section{Methodology:-}

$200 \mathrm{gm}$ of lubricating oil sample is placed in a $500 \mathrm{ml}$ round flask with condenser. The round flask was then placed into a water bath with a magnetic stirring system (ADVANTEC, USA). The prepared solvent mixture was added to the flask according to the specified feed to solvent ratio. Different percent of phenol $(25 \%, 50 \%$ and $75 \%)$ in the solvent mixture was tested. Mixture was agitated using magnetic stirrer for 15 minutes, at the end of the experiments, mixture was placed in a separation funnel for $1 \mathrm{hr}$. Two layers were separated; the top raffinate layer and the bottom extract layer. The extract contains solvent with the dissolved aromatic compounds, while the raffinate contains lubricating oil after the extraction of aromatic compounds. The raffinate was separated and analyzed.

Experiments were conducted in 6 sets of experiments. In the first three sets of experiments, Table 3, extraction temperature of $65{ }^{\circ} \mathrm{C}$, feed to solvent ratio of $1: 1,1: 1.5$ and $1: 2$ were used. The amount of phenol in the solvent blend was varied $(0 \%, 25 \%, 50 \%, 75 \%$ and $100 \%)$. All other variables are kept constant. In the fourth and fifth set of experiments, see Table 4, percent of phenol in solvent was kept constant at $25 \%$ and $75 \%$ respectively. The feed to solvent ratio was kept at 1: 2 while the extraction temperature changed from $65{ }^{\circ} \mathrm{C}$ to $112^{\circ} \mathrm{C}$. The effect of solvent ratio variation on 5 specifications; viscosity, viscosity index, conradson carbon residue, color, refractive index and yield were studies. 
Refractive index was conducted according to ASTM D-1218 using Abbe Refractometer, VEE GEE Model C10 (Thomas scientific). Also, Kinematic viscosity was measured according to ASTM D445 at $100{ }^{\circ} \mathrm{C}$ and at $40{ }^{\circ} \mathrm{C}$. Color was measured according to ASTM D-1500. Conradson carbon residue apparatus, Model 80030 (Koehler, USA) confirming with ASTM D-189 was used.

After identifing the optimum: feed to solvent ratio, percent of phenol in solvent and extraction temperature, different concentrations of sodium lauryl ether sulfate $(0.01,0.02,0.05$ and $0.1 \mathrm{wt} . \%)$ were added to the mixture, see Table $\mathbf{5}$ to study the effect of surfactant on the performance of the co-solvent under study.

Table 3: List of experiments variables studied (set 1, 2 and 3 of experiments) at constant extraction temperature of $65^{\circ} \mathrm{C}$ and mixing time of 15 minutes.

\begin{tabular}{|c|c|c|c|c|c|}
\hline \multicolumn{6}{|c|}{ Set 1 of Experiments } \\
\hline Experiment No. & $\# 1$ & $\# 2$ & $\# 3$ & $\# 4$ & $\# \mathbf{5}$ \\
\hline Feed to Solvent ratio & \multicolumn{5}{|c|}{$1: 1$} \\
\hline \% Phenol in solvent & 0 & $25 \%$ & $50 \%$ & $75 \%$ & $100 \%$ \\
\hline \% NMP in solvent & $100 \%$ & $75 \%$ & $50 \%$ & $25 \%$ & 0 \\
\hline \multicolumn{6}{|c|}{ Set 2 of Experiments } \\
\hline Experiment No. & $\# 6$ & $\# 7$ & $\# 8$ & $\# 9$ & \# 10 \\
\hline Feed to Solvent ratio & \multicolumn{5}{|c|}{$1: 1.5$} \\
\hline \% Phenol in solvent & 0 & $25 \%$ & $50 \%$ & $75 \%$ & $100 \%$ \\
\hline \% NMP in solvent & $100 \%$ & $75 \%$ & $50 \%$ & $25 \%$ & 0 \\
\hline \multicolumn{6}{|c|}{ Set 3 of Experiments } \\
\hline Experiment No. & \# 11 & $\# 12$ & \# 13 & $\# 14$ & \# 15 \\
\hline Feed to Solvent ratio & \multicolumn{5}{|c|}{$1: 2$} \\
\hline \% Phenol in solvent & 0 & $25 \%$ & $50 \%$ & $75 \%$ & $100 \%$ \\
\hline \% NMP in solvent & $100 \%$ & $75 \%$ & $50 \%$ & $25 \%$ & 0 \\
\hline
\end{tabular}

Table 4: List of experiments variables studied (set 4 and 5 of experiments) at constant feed to solvent ratio of 1:2 and constant mixing time of 15 minutes.

\begin{tabular}{|c|c|c|c|c|c|c|}
\hline \multicolumn{7}{|c|}{ Set 4 of Experiments } \\
\hline Experiment No. & \# 12 & \# 16 & \# 17 & \# 18 & \# 19 & $\# \mathbf{2 0}$ \\
\hline$\%$ Phenol in solvent & \multicolumn{6}{|c|}{$25 \%$} \\
\hline \% NMP in solvent & \multicolumn{6}{|c|}{$75 \%$} \\
\hline Temperature, ${ }^{\circ} \mathrm{C}$ & 65 & 90 & 97 & 103 & 108 & 112 \\
\hline \multicolumn{7}{|c|}{ Set 5 of Experiments } \\
\hline Experiment No. & $\# 14$ & $\# 21$ & \# 22 & \# 23 & $\# 24$ & $\# 25$ \\
\hline$\%$ Phenol in solvent & \multicolumn{6}{|c|}{$75 \%$} \\
\hline \% NMP in solvent & \multicolumn{6}{|c|}{$25 \%$} \\
\hline Temperature, ${ }^{\circ} \mathrm{C}$ & 65 & 90 & 97 & 103 & 108 & 112 \\
\hline
\end{tabular}

Table 5: List of experiments variables studied (set 6 of experiments) at different concentrations of surfactant SLS, constant feed to solvent ratio of $1: 2,103{ }^{\circ} \mathrm{C}$ extraction temperature and constant mixing time of 15 minutes.

\begin{tabular}{|c|c|c|c|c|c|}
\hline \multicolumn{6}{|c|}{ Set 6 of Experiments } \\
\hline Experiment No. & \# 18 & \# 26 & \# 27 & \# 28 & \# 29 \\
\hline wt. \% surfactant (SLS) & 0 & 0.01 & 0.02 & 0.05 & 0.1 \\
\hline$\%$ Phenol in solvent blend & $25 \%$ & $25 \%$ & $25 \%$ & $25 \%$ & $25 \%$ \\
\hline$\%$ NMP in solvent blend & $75 \%$ & $75 \%$ & $75 \%$ & $75 \%$ & $75 \%$ \\
\hline
\end{tabular}

\section{Results and Discussion:-}

Different experiments were conducted to test the effect of NMP/Phenol co-solvent without and with the present of SLS as an additive to the mixture. Results are listed in Table 6, a graphical representation of the data are shown in Figure 1, 2 and 3 for comparison. 
Conradson carbon residue is a measure of the amount of carbon deposits that can form during the combustion of lubricating oil. A higher value of conradson carbon residue indicate a low-quality lubricating oil. The Egyptian standards limit for Conradson carbon residue is 0.015 wt. $\%$. According to Table $\mathbf{6}$ and Figure 1-a, the amount of carbon residue in the raffinate decreases with the increase in the \% phenol present in the NMP/phenol solvent mixture up to a value of 50\% phenol. Any further increase in the amount of phenol present in the solvent mixture causes the conradson carbon residue of the raffinate to increase. The performance of the $25 \%$ phenol-75\% NMP solvent mixture was even better than that of NMP alone, specially at high feed to solvent ratio of 1:2. The highest carbon residue value of $0.018 \mathrm{wt}$. $\%$ was obtained at $100 \%$ phenol while a low value of $0.009 \mathrm{wt} . \%$ of carbon residue was reached when using $25 \%$ pheno- $75 \%$ NMP solvent mixture.

Same trend was observed with the refractive index measurement, see Table 6 and Figure 1-b, a decrease in the refractive index value was observed with the increase in the feed to solvent ratio. Refractive index is an indication of the aromatic content in the raffinate, a higher refractive index value indicates high aromatic content and vice versa. The lowest refractive index value of 1.4540 was reached when using $25 \%$ phenol $-75 \%$ NMP solvent mixture and when using $100 \%$ NMP at a feed to solvent ratio of 1:2. In addition, an increase in viscosity measured at both $40^{\circ} \mathrm{C}$ and $100^{\circ} \mathrm{C}$ was observed with the increase in the \% phenol present in solvent, see Table 6, Figure 1-c and Figure 1d. Improvement in viscosity index was observed at low \% of phenol, see Table 6 and Figure 1-e. The highest viscosity index value of 104 and 102 was reached when using 100\% NMP and 25\% phenol-75\% NMP solvent respectively at 1:2 feed to solvent ratio. Analysis of Figure 1-a to Figure 1-e confirm that 25\%phenol-75\%NMP has high selectivity to aromatic compounds comparable to that of $100 \%$ NMP solvent and better than that of other phenol solvent mixtures.

Highest raffinate yield of $90.8 \%$ was obtained by using $25 \%$ phenol-75\% NMP solvent mixture at $1: 1$ feed to solvent ratio, while the lowest raffinate yield of $67 \%$ was obtained at $100 \%$ phenol with 1:2 feed to solvent ratio, see Table 6 and Figure 1-f. Yield is affected by the feed to solvent ratio, the higher the feed to solvent ratio the lower the raffinate yield. It can be inferred from Figure 1-f that 25\%phenol-75\% NMP has moderate solvency power and high selectivity. In addition, the cost of this solvent mixture is lower than that of pure NMP solvent, while the phenol toxicity is diluted by the NMP solvent. Hence this mixture is considered an optimum mixture and will be further investigated at different extraction temperature.

Different extraction temperature was investigated using 25\% phenol-75\% NMP solvent mixture as an optimum solvent blend. In this study 75\% phenol-25\% NMP solvent was used for comparison. According to Table 6 and Figure 2-a, it was found that carbon residue decreases with the increase in extraction temperature, up to $103{ }^{\circ} \mathrm{C}$ where a value of 0.004 wt. $\%$ of residue carbon is obtained. Any further increase in temperature above the $103^{\circ} \mathrm{C}$, causes the carbon residue in raffinate to increases. Same behavior was observed for raffinate refractive index measurements, with the increase in extraction temperature, see Table 6 and Figure 2-b. A minimum value of 1.4538 for refractive index was obtained at extraction temperature of $103{ }^{\circ} \mathrm{C}$ by using $25 \%$ phenol-25\% NMP solvent mixture. This trend in the refractive index and conradson carbon residue was confirmed by the viscosity and viscosity index measurements, Table 6, Figure 2-c, Figure 2-d and Figure 2. This shows an increase in selectivity till the optimum extraction temperature (near the critical temperature) after which loss of selectivity is observed.

Table 6: Properties of the raffinate analyzed after solvent extraction; Experiments set 1 to 6.

\begin{tabular}{|c|c|c|c|c|c|c|}
\hline \multicolumn{6}{|c|}{ Results for Set 1 of Experiments } & \multirow{2}{*}{$\begin{array}{c}\text { Lubricating Oil sample } \\
\text { before treatment }\end{array}$} \\
\hline Experiment No. & $\# 1$ & $\# \mathbf{2}$ & \# 3 & \# 4 & \# 5 & \\
\hline Viscosity @100 ${ }^{\circ} \mathrm{C}$ & 3.19 & 4.11 & 4.55 & 4.8 & 3.5 & 5.2 \\
\hline Viscosity @ 40 ${ }^{\circ} \mathrm{C}$ & 13.80 & 21.05 & 25.50 & 28.30 & 16.58 & 34.8 \\
\hline Viscosity Index & 90 & 90 & 85 & 83 & 79 & 67 \\
\hline Conradson Carbon & 0.016 & 0.014 & 0.017 & 0.018 & 0.018 & 0.038 \\
\hline Color & 2.5 & 2.5 & 2.5 & 3 & 3 & 3.5 \\
\hline Refractive Index & 1.4590 & 1.4589 & 1.4604 & 1.4610 & 1.4600 & 1.4700 \\
\hline Yield \% & 90 & 90.8 & 87.5 & 85 & 77 & - \\
\hline \multicolumn{6}{|c|}{ Results for Set 2 of Experiments } & Lubricating Oil sample \\
\hline Experiment No. & $\# 6$ & $\# 7$ & \# 8 & $\# 9$ & \#10 & before treatment \\
\hline Viscosity @ 100 ${ }^{\circ} \mathrm{C}$ & 3.22 & 3.69 & 3.66 & 3.71 & 3.28 & 5.2 \\
\hline Viscosity @ 40 ${ }^{\circ} \mathrm{C}$ & 13.65 & 17.20 & 17.16 & 17.65 & 14.42 & 34.8 \\
\hline
\end{tabular}




\begin{tabular}{|c|c|c|c|c|c|c|c|}
\hline Viscosity Index & 100 & \multicolumn{2}{|c|}{98} & 94 & 92 & 91 & 67 \\
\hline Conradson Carbon & 0.013 & 0.009 & & 0.0011 & 0.016 & 0.015 & 0.038 \\
\hline Color & 2.0 & \multicolumn{2}{|c|}{2.0} & 2.0 & 2.5 & 2.5 & 3.5 \\
\hline Refractive Index & \multirow{2}{*}{1.4565} & 1.4565 & & 1.4570 & 1.4575 & 1.4570 & 1.4700 \\
\hline Yield \% & & \multicolumn{2}{|c|}{85.8} & 83.8 & 82.5 & 75 & \multirow{3}{*}{$\begin{array}{c}- \\
\begin{array}{c}\text { Lubricating Oil sample } \\
\text { before treatment }\end{array}\end{array}$} \\
\hline \multicolumn{7}{|c|}{ Results for Set 3 of Experiments } & \\
\hline Experiment No. & \# 11 & \multicolumn{2}{|c|}{ \#12 } & \#13 & \#14 & \# 15 & \\
\hline Viscosity @ 100 ${ }^{\circ} \mathrm{C}$ & 3 & \multicolumn{2}{|c|}{3.4} & 3.45 & 3.44 & 3.05 & 5.2 \\
\hline Viscosity@ $90^{\circ} \mathrm{C}$ & 12.00 & \multicolumn{2}{|c|}{14.80} & 15.34 & 15.39 & 12.66 & 34.8 \\
\hline Viscosity Index & \multirow{2}{*}{$\begin{array}{c}104 \\
0010\end{array}$} & \multicolumn{2}{|c|}{102} & 99 & 96 & 95 & 67 \\
\hline Conradson Carbon & & 0.0 & & 0.009 & 0.013 & 0.012 & 0.038 \\
\hline Color & 1.5 & 1. & & 2.0 & 2.0 & 2.0 & 3.5 \\
\hline Refractive Index & 1.4540 & 1.45 & & 1.4548 & 1.4547 & 1.4545 & 1.4700 \\
\hline Yield \% & 81 & 8 & & 79 & 76 & 73 & - \\
\hline & Results & or Set 4 & f Experir & iments & & & Lubricating Oil sample \\
\hline Experiment No. & \#12 & \# 16 & \# 17 & \begin{tabular}{l|l} 
& $\#$ \\
\end{tabular} & \# 19 & \# 20 & before treatment \\
\hline Viscosity @ 100 ${ }^{\circ} \mathrm{C}$ & 3.4 & 3.24 & 3.15 & 3. & 3.23 & 3.52 & 5.2 \\
\hline Viscosity @ 40º $\mathrm{C}$ & 14.8 & 13.58 & 12.85 & 11. & 13.38 & 15.63 & 34.8 \\
\hline Viscosity Index & 102 & 104 & 107 & 10 & 107 & 103 & 67 \\
\hline Conradson Carbon & 0.009 & 0.008 & 0.005 & 0.0 & 0.008 & 0.011 & $\mathbf{0 . 0 3 8}$ \\
\hline Refractive Index & 1.4540 & 1.4538 & 1.4536 & 1.4 & 1.4539 & 1.4546 & 1.4700 \\
\hline Yield \% & 80 & 73 & 71 & 6 & 65 & 62 & - \\
\hline & Results & or Set 5 & f Experir & iments & & & Lubricating Oil sample \\
\hline Experiment No. & \# 14 & \# 21 & \# 22 & \begin{tabular}{l|l} 
& $\# 2$ \\
\end{tabular} & \# 24 & $\# 25$ & before treatment \\
\hline Viscosity @ 100 ${ }^{\circ} \mathrm{C}$ & 3.44 & 3.32 & 3.10 & 2. & 3.04 & 3.19 & 5.2 \\
\hline Viscosity @ 40 ${ }^{\circ} \mathrm{C}$ & 15.39 & 14.43 & 12.82 & 11. & 12.45 & 13.70 & 34.8 \\
\hline Viscosity Index & 96 & 98 & 100 & 10 & 99 & 93 & 67 \\
\hline Conradson Carbon & 0.013 & 0.01 & 0.009 & 0.0 & 0.011 & 0.015 & $\mathbf{0 . 0 3 8}$ \\
\hline Refractive Index & 1.4547 & 1.4548 & 1.4544 & 1.4 & 1.4546 & 1.4553 & 1.4700 \\
\hline Yield \% & 76 & 71 & 70 & 7 & 68 & 67 & - \\
\hline & Results & or Set 6 & f Experir & iments & & & Lubricating Oil sample \\
\hline Experiment No. & \# 18 & \# 20 & & $\# 27$ & \# 28 & \# 29 & before treatment \\
\hline Viscosity Index & 109 & 111 & & 113 & 113 & 114 & 67 \\
\hline Refractive index & 1.4535 & 1.45 & & .4529 & 1.4527 & 1.4525 & 1.4700 \\
\hline Yield, \% & 69 & 72 & & 74 & 77 & 80 & - \\
\hline
\end{tabular}




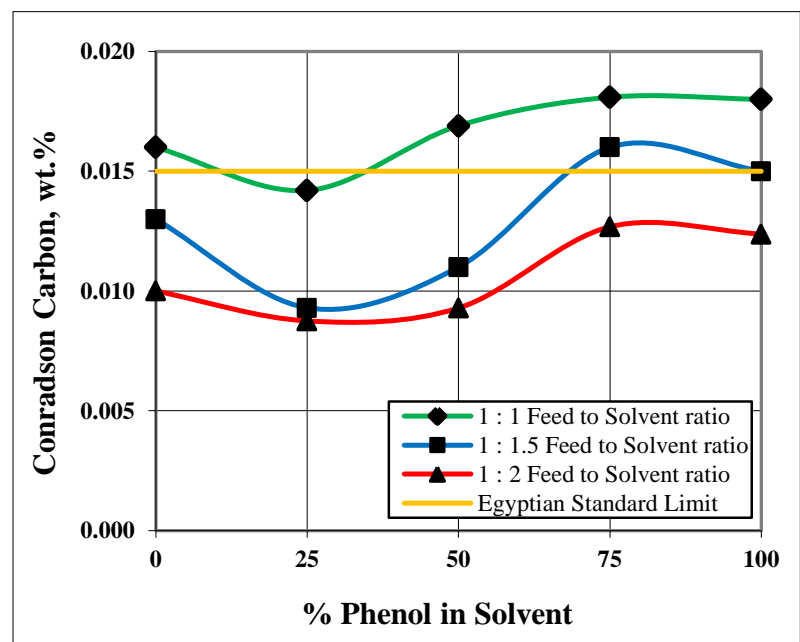

(a)

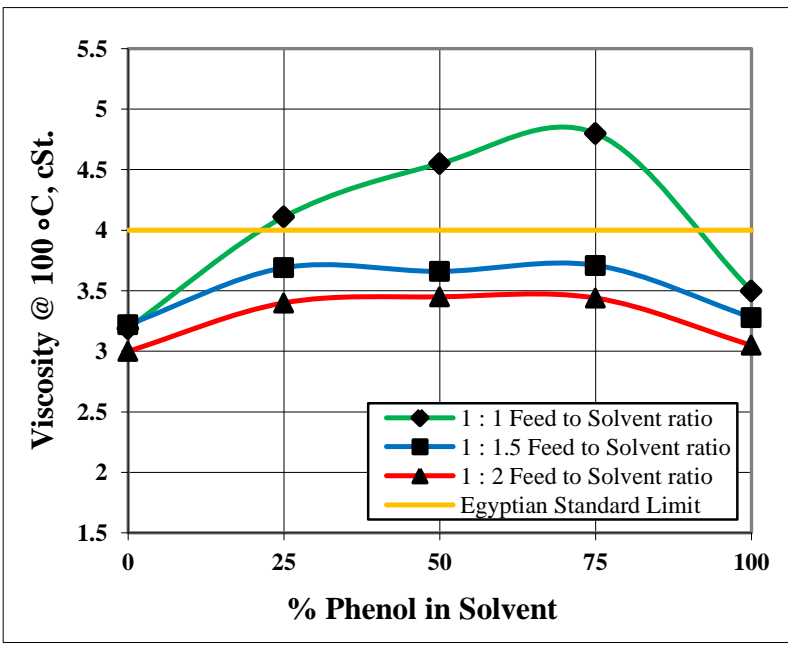

(c)

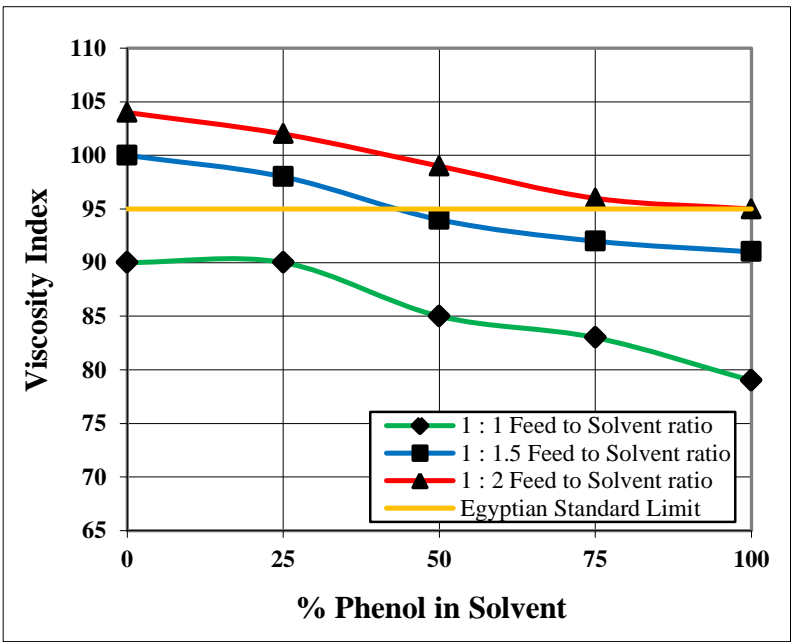

(e)

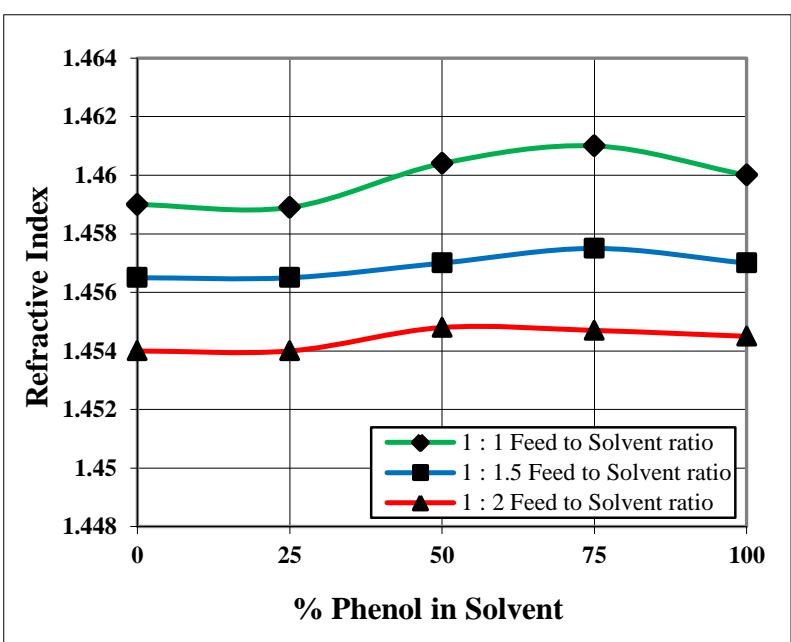

(b)

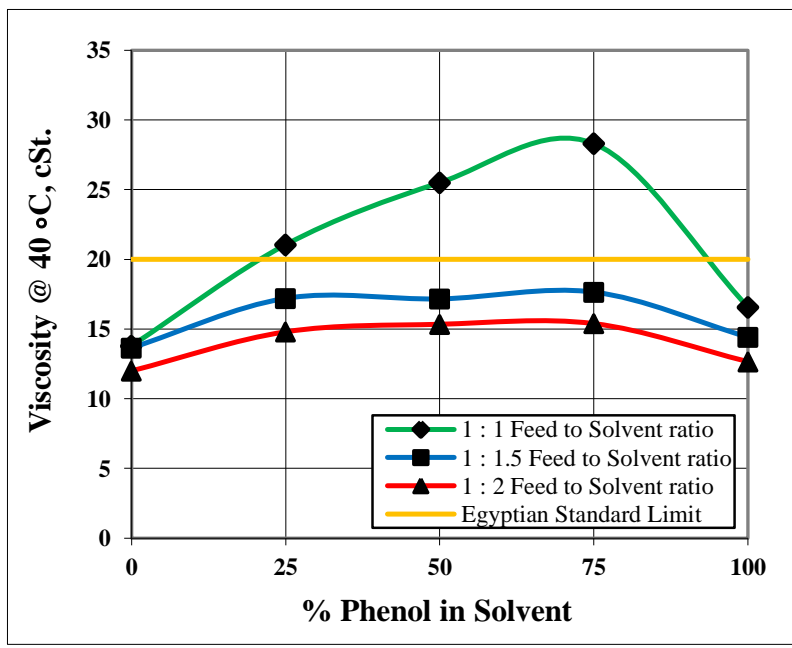

(d)

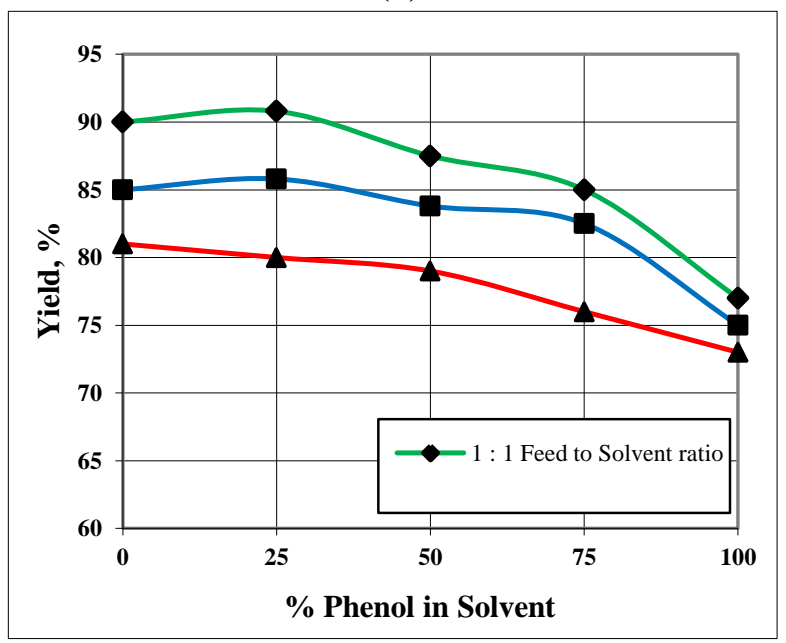

(f)

Figure 1: Properties of the raffinate after solvent extraction; experiments set $1-3$, solvent to feed ratio and $\%$ of phenol in solvent mixture were changed at constant extraction temperature of $65{ }^{\circ} \mathrm{C}$ and mixing time of 15 minutes; (a) Conradson Carbon Residue, (b) Refractive Index, (c) Viscosity measured at $100^{\circ} \mathrm{C}$, (d) Viscosity measured at $40^{\circ} \mathrm{C}$, (e) Viscosity Index and (f) $\%$ Yield. 


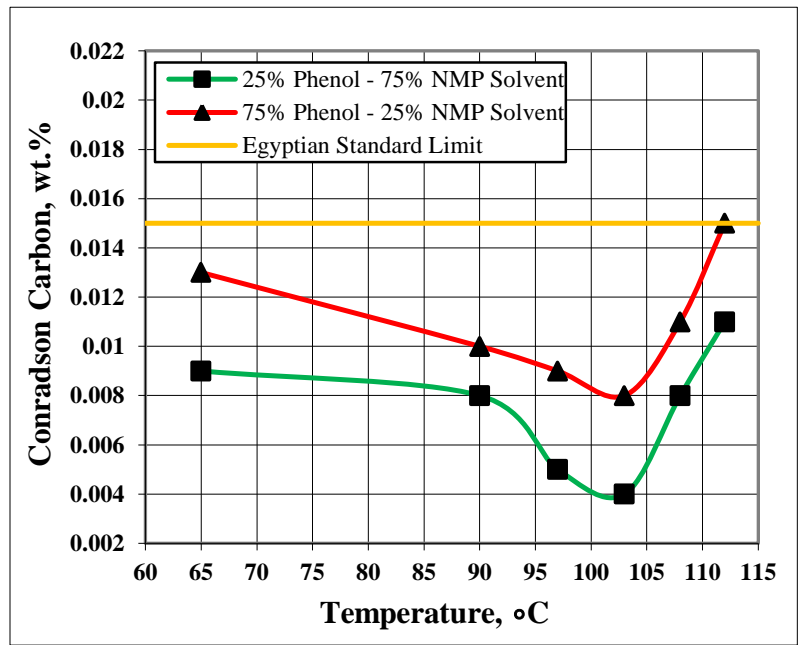

(a)

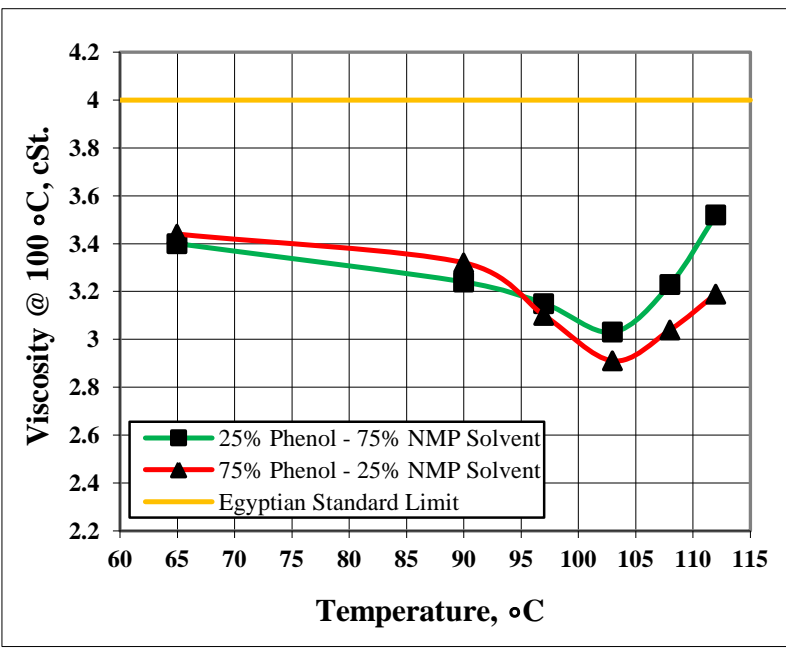

(c)

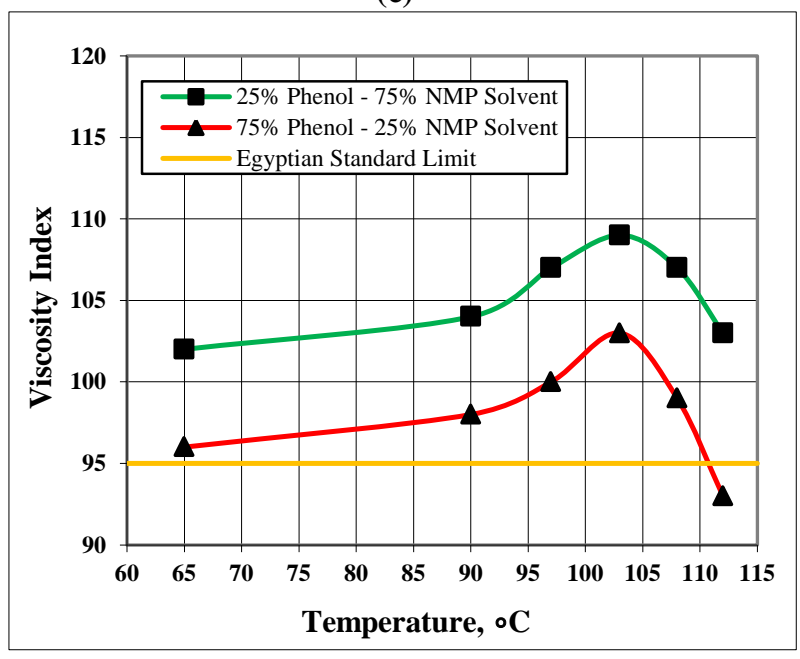

(e)
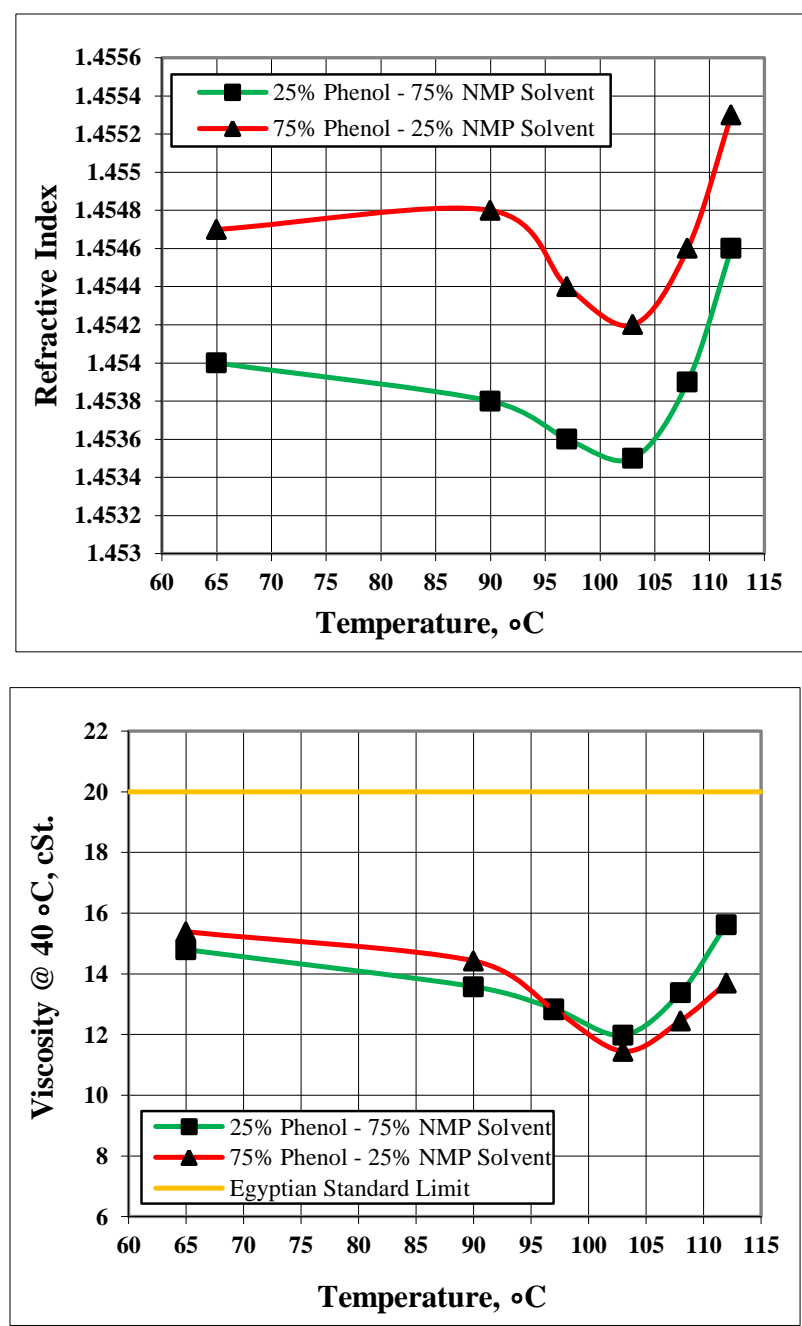

(b)

(d)

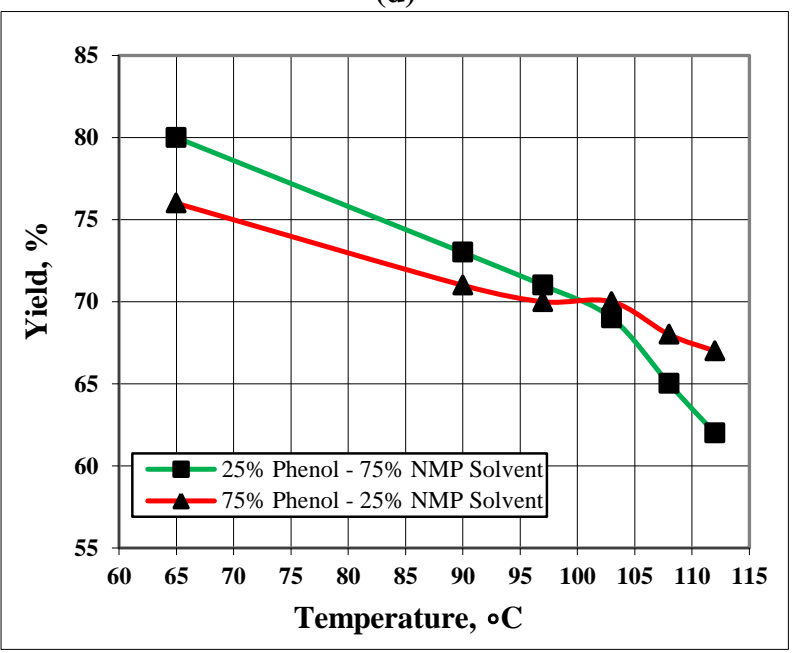

(f)

Figure 2: Properties of the raffinate after solvent extraction; experiments set 4 and 5, the extraction temperature and $\%$ of phenol in solvent was changed while Feed to Solvent ratio of 1:2 and mixing time of 15 minutes were held 
constant; (a) Conradson Carbon Residue, (b) Refractive Index, (c) Viscosity measured at $100^{\circ} \mathrm{C}$, (d) Viscosity measured at $40^{\circ} \mathrm{C}$, (e) Viscosity Index and (f) $\%$ Yield.

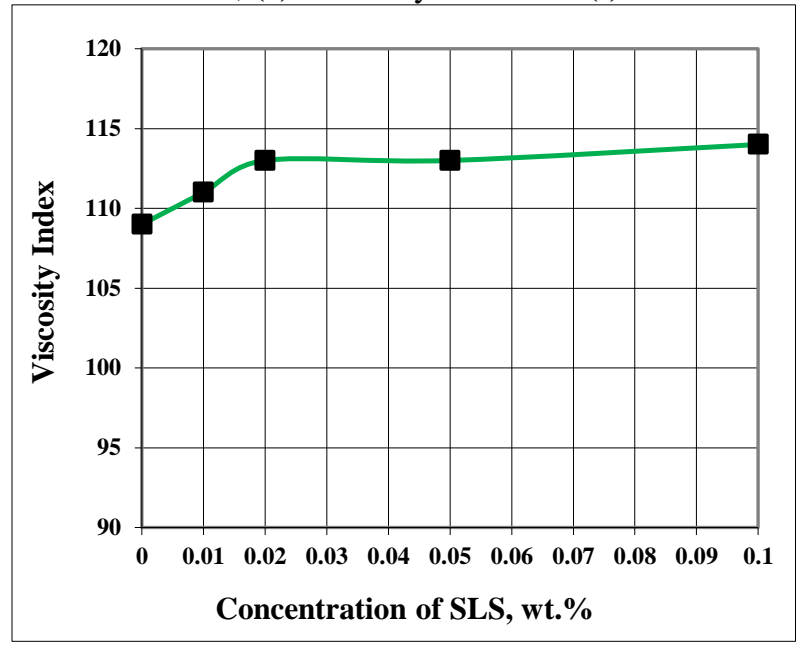

(a)

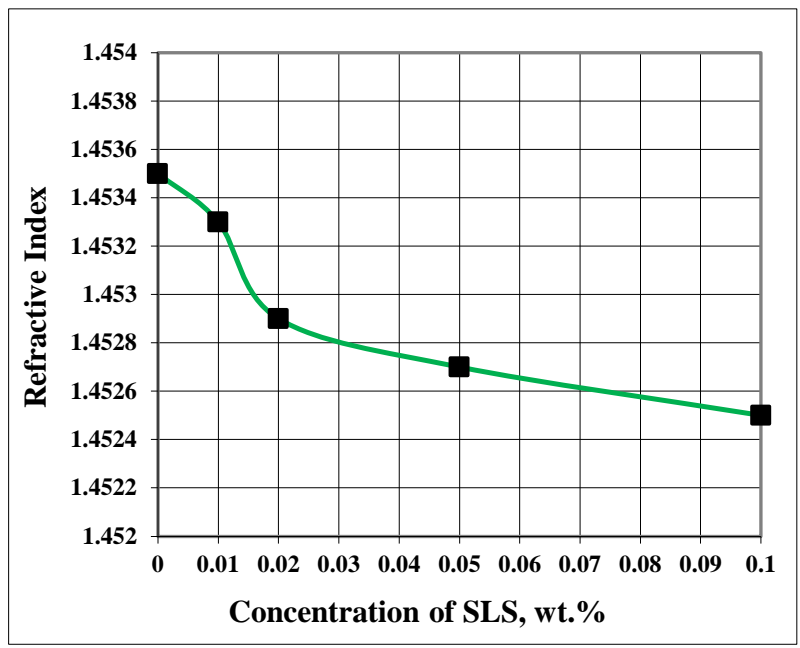

(b)

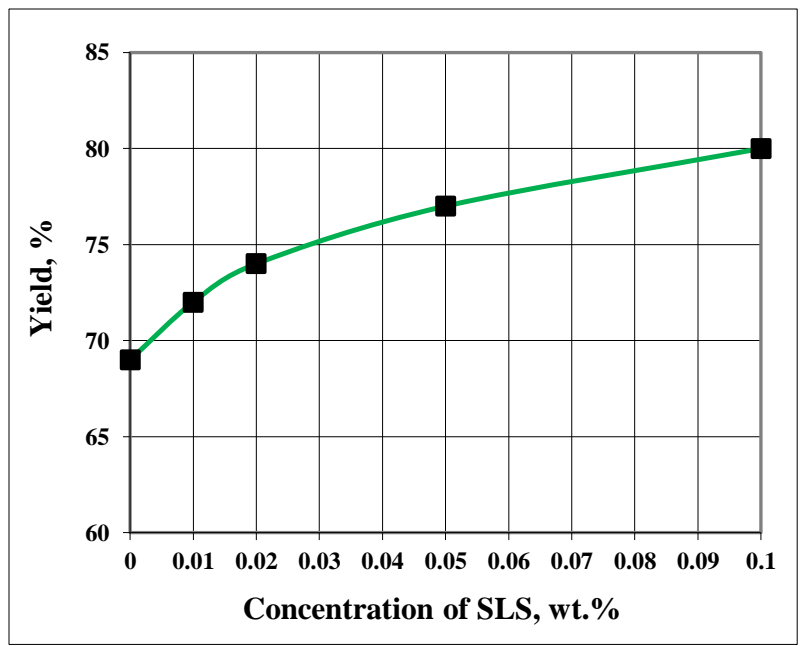

(c)

Figure 3: Properties of the raffinate after solvent extraction with 25\% phenol-75\% NMP and SLS as an additive; experiments set 6 . The amount of SLS added to the solvent mixture was varied at constant extraction temperature of $103{ }^{\circ} \mathrm{C}$, Feed to Solvent ratio of 1:2 and mixing time of 15 minutes; (a) Viscosity Index, (b) Refractive Index, (c) \% Yield.

One the other hand, the amount of raffinate, $\%$ yield decreased continuously with the increase in extraction temperature, Table 6 and Figure 2-f, a value to $69 \%$ was obtained at an optimum extraction temperature of $103{ }^{\circ} \mathrm{C}$. This reflect an increase in the solvency power with the increase in temperature.

In all cases the 25\% phenol-75\% NMP solvent mixture performed better than the $75 \%$ phenol-25\% NMP solvent mixture. By the analysis of the results, the optimum operating condition is at temperature of $103^{\circ} \mathrm{C}$, feed to solvent ratio of 1:2 and 25\% phenol-75\% NMP solvent mixture. This was used as a starting point for the investigation of the effect of surfactant as an additive. Different amount of SLS was used as listed in Table 5, the resulting raffinate was analyzed and data was listed in Table 6. As can be seen from Figure 3, the addition of surfactant to the solvent mixture increased the selectivity of solvent from aromatic compounds. This was confirmed from the increase in the viscosity index and the refractive index with the increase in the amount of SLS added, Figure 3-a and Figure 3-b. The highest increase was achieved by the addition of $0.02 \mathrm{wt} . \%$ of SLS surfactant. Further addition of surfactant 
increased the viscosity index and refractive index but to a lesser extent. Moreover, the raffinate yield increased with the continuous addition of SLS surfactant to the solvent, Figure 3-c. This means that the solvent power was reduced with the addition of surfactant which enhanced the phase separation while in the same time increased the solvent selectivity.

\section{Conclusion:-}

Solvent extraction of lubricating oil was investigated using NMP and Phenol solvent blend. The effect of surfactant as an additive to the mixture was also tested. The feed to solvent ratio, the percent of phenol in the solvent blend, the extraction temperature and the amount of SLS surfactant added was changed, the resulting raffinate was tested. It was found that:

- The higher the feed to solvent ratio the better the properties of the resulting raffinate.

- Increasing the percent of phenol in the solvent mixture at the same feed to solvent ratio and at constant temperature, decrease the quality of the lubricating oil.

- The best lubricating oil quality was obtained at 25\% phenol-75\% NMP even better than using 100\% NMP solvent at 1:2 feed to solvent ratio.

- Increasing the extraction temperature improves the properties of lubricating oil till an optimum temperature of $103{ }^{\circ} \mathrm{C}$ is reached above which the quality of the oil become worse.

- The addition of surfactant in small quantities up to $0.02 \mathrm{wt} . \%$ improves the properties of the lubricating oil.

- The best combination of extraction condition to get high quality lubricating oil is to, use $25 \%$ phenol-75\% NMP solvent blend in $1: 2$ feed to solvent ratio at $103{ }^{\circ} \mathrm{C}$ extraction temperature, with the option to add $0.02 \mathrm{wt} . \%$ of SLS surfactant.

\section{References:-}

1. Lubricants Market Size, Share \& Trends Analysis Report By Product (Industrial, Automotive, Marine, Aerospace), By Region, And Segment Forecast, 2019 - 2025, Grand View Research.

2. Lutz Lindemann, Future Challenges of the lubricants Industry, FUCHS Capital Market Day 2018

3. McKetta, J.J.: Encyclopedia of Chemical Processing and Design. Marcel Dekker, Inc, New York (1989)

4. Nelson, W.L. : Petroleum Refining Engineering. McGraw-Hill, New York (1978)

5. Sequeira, A. Jr.: Lubricant Base Oil and Wax Processing. pp. 81-82. Marcel Dekker, New York (1994)

6. Mohammed, Abdul-Halim A-K., Hussain K. Hussain, and Rafal J. Sadiq. "The Effect of Solvent Extraction of Light Lubricating Oil on Viscosity Index and Chemical Composition." Iraqi Journal of Chemical and Petroleum Engineering 8, no. 4 (2007): 1-12.

7. De Lukas, L. Rodriguez, P. Snchez, and A. Carnicer. "Extraction of aromatic compounds from heavy natural distillate lubricating oil by using furfural." Sep. Sci. Technol. 28, (1993): 2465-2477.

8. Coto, R.van Grieken, J. L. Pena, and J. J. Spada. "A model to predict physical properties for light lubricating oils and its application to the extraction process by furfural." Chem. Eng. Sci. 61, (2006): 4381-4392.

9. Kheder, Mohammed J. Yass, and Abdul-Halim A. Mohammed. "The effect of extraction temperature and solvent to oil ratio on viscosity index of mixed-medium lubricating oil fraction by using solvents extraction." Iraqi journal of chemical and petroleum engineering 10, no. 2 (2009): 13-18.

10. Qasim, Muslim A. "Extraction of aromatic hydrocarbons from lube oil using different co-solvent." Iraqi Journal of Chemical and Petroleum Engineering 16, no. 1 (2015): 79-90.

11. F. H. Garner and A. R. Hale. "The effects of surface-active agents in liquid extraction processes." Chem. Eng. Sci. 2, (1953):157-163.

12. W. S. Huang, and R. C. Kintner. "Effects of surfactants on mass transfer inside drops." AICHE J. 15, (1969): 735744.

13. J. S. Horgn, and J. R. Maa. "The effect of a surfactant on mixer-settler operation.” J. Chem. Technol. Biotechnol. 36, (1986): 15-26.

14. P. Mulyono, and S. Muliati. "Effect of surfactant on single drop mass transfer in liquid-liquid extraction." AJChE 7, no. 1, (2007): 15-26.

15. A. Audeh, J. Israel, and J. R. Heilwel. "White. Solvent extraction production of lube oil fractions." (1983), US patent, 4381234.

16. H. Izza, and M. Korichi. "Extraction of aromatic from lube oil using a surfactant as an additive." Petroleum Science and Technology 35, no. 2 (2017): 201-205.

17. Hidaya Izza, and Mourad Korichi. "The Effect of Surfactant on Selectivity in the Extraction of Aromatic Hydrocarbons from the Lube Oil." Arabian Journal for Science and Engineering 41, no. 7 (2016): 2623-2629.

18. Patrick J. Sinko: Martin's Physical Pharmacy and Pharmaceutical Sciences, $5^{\text {th }}$ ed., Lippincott Williams \& Wilkins (2005). 